\title{
O ensino de ciências da vida e da natureza aos surdos: o que dizem importantes periódicos da área a respeito?
}

The teaching of life and nature sciences to the deaf: what do important journals in the area say about it?

La enseñanza de ciencias de la vida y de la naturaleza a los sordos: ¿qué dicen importantes revistas del área al respecto?

Célio da Silveira Júnior

Professor doutor da Universidade Federal de Minas Gerais, Belo Horizonte, MG, Brasil

E-mail: celiosilveirajr@yahoo.com.br ORCID: https://orcid.org/0000-0003-0967-520X

Juarez Melgaço Valadares

Professor doutor da Universidade Federal de Minas Gerais, Belo Horizonte, MG, Brasil

E-mail: juarezmelgaco@gmail.com ORCID: https://orcid.org/0000-0001-8950-1490

Reginaldo Silva Guimarães

Professor da Prefeitura Municipal de Belo Horizonte, Belo Horizonte, MG, Brasil

E-mail: reginaldosg@yahoo.com.br ORCID: https://orcid.org/0000-0003-2998-6152

Recebido em 22 de abril de 2020

Aprovado em 19 de março de 2021

Publicado em 12 de abril de 2021

\section{RESUMO}

Há uma série de necessidades a serem atendidas para uma efetiva inclusão escolar dos surdos, em especial no que se refere às ciências da vida e da natureza. Uma delas diz respeito à construção e desenvolvimento de estratégias metodológicas adequadas para o ensino de estudantes surdos. Para se ter um panorama das produções recentes envolvendo o ensino de ciências a estudantes surdos, este trabalho teve como objetivo mapear as publicações feitas nos últimos 5 anos em alguns dos importantes periódicos da área de ensino e/ou de educação em ciências da vida e da natureza. Os resultados apontaram para o baixo número de publicações a tratar do ensino de ciências para estudantes surdos. Duas hipóteses são sugeridas para a discussão desse contexto. Uma delas seria a de que esses trabalhos têm sido publicados em quantidades e qualidades significativas sob outros formatos ou em outros periódicos. Outra hipótese, mais preocupante, é a de que esses trabalhos realmente não têm sido desenvolvidos e publicados, apesar da importância que eles teriam para a inclusão escolar dos surdos em relação à educação em ciências.

Palavras-chave: Ensino de ciências; Inclusão escolar; Estudantes surdos.

\section{ABSTRACT}

There are a number of needs to be met for an effective school inclusion of deaf people, especially with regard to life and nature sciences. One of them concerns the construction and development of appropriate methodological strategies for teaching deaf students. To 
http://dx.doi.org/10.5902/1984686X43701

get an overview of recent productions involving teaching science to deaf students, this work aimed to map the publications made in the last 5 years in some of the important journals in the area of teaching and/or education in life and nature sciences. The results pointed to the low number of publications dealing with science teaching for deaf students. Two hypotheses are suggested for discussion of this context. One of them would be that these works have been published in significant quantities and qualities under other formats or in other journals. Another hypothesis, more worrisome, is that these works have not really been developed and published, despite the importance that they would have for the school inclusion of deaf people in relation to science education.

Keywords: Science education; School inclusion; Deaf students.

\section{RESUMEN}

Hay una serie de necesidades a ser atendidas para una efectiva inclusión escolar de los sordos, en particular en lo que se refiere a las ciencias de la vida y de la naturaleza. Una de ellas se refiere a la construcción y desarrollo de estrategias metodológicas adecuadas para la enseñanza de estudiantes sordos. Para tener un panorama de las producciones recientes involucrando la enseñanza de ciencias a estudiantes sordos, este trabajo tuvo como objetivo mapear las publicaciones realizadas en los últimos 5 años en algunos de los importantes periódicos del área de enseñanza y/o de educación en ciencias de la vida y de la naturaleza. Los resultados apuntaron al bajo número de publicaciones que se ocupan de la enseñanza de ciencias para estudiantes sordos. Dos hipótesis se sugieren para la discusión de ese contexto. Una de ellas sería que estos trabajos han sido publicados en cantidades y calidades significativas bajo otros formatos o en otras revistas. Otra hipótesis, más preocupante, es que estos trabajos realmente no han sido desarrollados y publicados, a pesar de la importancia que tendrían para la inclusión escolar de los sordos en relación a la educación en ciencias.

Palabras clave: Enseñanza de las ciencias; Inclusión escolar; Estudiantes sordos.

\section{A inclusão escolar de estudantes surdos}

Segundo os dados estimados pela Pesquisa Nacional de Saúde, divulgados pelo IBGE em 2015, 1,1\% da população brasileira possui deficiência auditiva, sendo esta constituída pela surdez nos dois ouvidos, pela surdez em um ouvido e reduzida no outro, e pela audição reduzida em ambos os ouvidos.

Há todo um conjunto de legislação e de diretrizes voltado para a inclusão social em geral dessa população e, em particular, para a sua inclusão escolar, em relação ao qual podemos citar a Declaração de Salamanca de 1994 (que trata de princípios, políticas e práticas na área das necessidades educativas especiais); a Constituição Federal de 1988 (que trata dos direitos e garantias fundamentais, e da ordem social); as leis números $7.853 / 1989$ (que dispõe sobre o apoio às pessoas portadoras de deficiência e sua 
integração social), 9.394/1996 (que estabelece as diretrizes e bases da educação nacional), $10.048 / 2000$ (que prioriza o atendimento às pessoas que especifica, dentre elas as com deficiência), 10.098/2000 (que estabelece normas gerais e critérios básicos para a promoção da acessibilidade das pessoas portadoras de deficiência ou com mobilidade reduzida), 10.436/2002 (que dispõe sobre a Língua Brasileira de Sinais - Libras), 10.845/2004 (que institui o programa de complementação ao atendimento educacional especializado às pessoas portadoras de deficiência) 12.319/2010 (que regulamenta a profissão de tradutor e intérprete de LIBRAS) e 13.146/2015 (que institui o estatuto da pessoa com deficiência); os decretos regulamentadores das leis citadas; e os Planos Nacionais de Educação de 2001 e de 2014 (que estabelecem diretrizes, objetivos, metas e estratégias relacionados à educação de surdos), dentre outros.

No entanto, sabemos que não basta a existência de um bem-intencionado conjunto de diretrizes para que as normativas nelas descritas se efetivem. Esse parece ser também o caso das políticas de inclusão escolar dos surdos. De acordo com Karnopp (2013), a falta de reconhecimento da língua de sinais, a carência de educação bilíngue, a disponibilidade limitada de serviços de interpretação e a generalizada desinformação sobre a situação das pessoas surdas mantêm-nas privadas de acesso a amplos setores da sociedade. Para Campos (2011), os direitos apontados nas leis existentes "não são colocados totalmente em prática em diversas instituições, e muitos surdos ainda enfrentam barreiras linguísticas e sociais" (p.30). Para a autora, "hoje o surdo encontra-se em conflito dada a política de inclusão no ensino regular" (p.32). Nesse mesmo sentido, Espote, Serralha e ScorsoliniComin (2013), em um trabalho de revisão da literatura sobre a inclusão de surdos, consideram ao final que:

Buscando avaliar como as formas de inclusão de deficientes auditivos tendem
a ocorrer exclusivamente na área da educação e compreender as lacunas
dos estudos na área, esta pesquisa encontrou que, apesar das leis que
regulamentam a educação inclusiva, de o assunto ser amplamente debatido
e dos esforços dos envolvidos, essa inclusão ainda não ocorre de maneira
eficaz, com uma prática muito diferente do que é proposto na política de
inclusão (ESPOTE, SERRALHA, SCORSOLINI-COMIN, 2013, p. 84).

Mas quais seriam os caminhos para a inversão desse quadro? Referências consideradas na elaboração deste texto apontam algumas das necessidades a serem atendidas para uma efetiva inclusão escolar dos surdos. Olhando primeiramente para a escola, é importante que o surdo não seja encapsulado em uma regra de normalidade. É por isso que a escola precisa favorecer aspectos de funcionamento que sejam 
http://dx.doi.org/10.5902/1984686X43701

condizentes com a diferença surda, considerando as necessidades e interesses individuais desses estudantes. É a escola que deveria se adaptar a eles, e não o contrário, onde os surdos sejam responsabilizados por suas aprendizagens. Nesse sentido, o que se espera é que haja uma inclusão escolar pensada a partir da diferença, que reconhece o indivíduo surdo como um sujeito sociocultural. Como bem diz Gesser (2008), os surdos não são todos iguais e nem vivem em uma clausura cultural. A escola, institucionalmente adequada à cultura surda ${ }^{1}$, busca contribuir para a construção da subjetividade desse sujeito, isto é, que a sua singularidade possa se constituir e ser ouvida no cotidiano das práticas escolares.

Para isso, também é preciso garantir que haja uma educação bilíngue para esses estudantes. No caso do Brasil, com a Língua Brasileira de Sinais (LIBRAS) como a primeira língua, e a língua portuguesa como a segunda. É a partir daí que seria possível aos surdos terem, na escola, um acesso mais facilitado a um conjunto de conhecimentos culturalmente construídos, ao mesmo tempo em que tomam curso os processos de constituição desses sujeitos sócio-históricos. Para Karnopp (2015), a língua de sinais é o principal marcador identitário da cultura surda. De acordo com Perlin e Strobel (2014), é por meio do uso da língua de sinais e da cultura surda que se dá o pertencimento ao povo surdo e a definição das identidades desses sujeitos. E, para Gesser (2008), a língua de sinais é um símbolo importante de identidade cultural ${ }^{2}$.

É na escola, onde se apresentem interlocutores que respeitem diferenças, que a linguagem desses sujeitos poderá se desenvolver de forma mais plena, desde que construída em situações significativas para eles. Assim, abrem-se possibilidades para a construção de relações comunicativas e para as trocas de conhecimentos. Nesse sentido, para uma melhor comunicação entre professor e estudantes e para uma melhor compreensão dos conteúdos discutidos, um aprofundamento em LIBRAS seria desejável para os professores de estudantes surdos.

Mas os cursos de formação docente, ainda que com a obrigatoriedade legal do ensino da LIBRAS, não têm dado conta de preparar o futuro professor para isso: faltam fundamentos teóricos e práticos para quem irá exercer essa função. E, dessa forma, uma indevida responsabilização da educação dos estudantes surdos é transferida para os intérpretes da língua de sinais. Em sentido contrário, pensar numa parceria entre o professor e o intérprete em todas as etapas dos processos de ensino e aprendizagem talvez seja mais profícuo: no planejamento, no desenvolvimento e na avaliação das 
http://dx.doi.org/10.5902/1984686X43701

atividades em sala de aula. No entanto, ainda que o professor seja proficiente em LIBRAS, a situação não está resolvida. Como nos diz Felipe (2013), nas línguas de modalidade gestual visual, como um discurso verbo-visual, há marcas não manuais no diálogo face a face que são essenciais para a completude do enunciado sinalizado para o interlocutor. Há também requisitos lexicais relacionados ao fato de que alguns sinais podem ter vários significados ou de que não existem sinais para determinados conceitos tratados. Além disso, os alunos surdos que atualmente chegam à escola possuem conhecimentos em níveis bem diversos de Libras.

Dado esse panorama, importante explicitar um aspecto que entendemos interessante: esses problemas só se tornaram explícitos porque houve a inclusão dos alunos. Anteriormente, o discurso era o de que devíamos estar plenamente preparados para trabalhar a inclusão destes grupos de alunos. Assim, nunca houve uma preocupação de fato: como nunca estivemos preparados, os alunos eram excluídos ou nem chegavam à escola. Seria uma exclusão travestida de inclusão, como foi classificada por Skliar e Quadros (2000). Diferentemente da situação atual, que tem uma natureza mais afirmativa.

As proposições elaboradas nesse cenário requerem uma boa contextualização, a fim de se minimizarem os equívocos que possam surgir, bem como é preciso pensar nas especificidades das disciplinas escolares a partir da construção de materiais didáticos e dicionários mais específicos. No caso das ciências da vida e da natureza, por exemplo, é importante considerar as características da linguagem científica, que pode se tornar uma barreira para a aprendizagem, em especial para os estudantes que não utilizam a linguagem oral, mas sim a gestual (BENITE, BENITE e VILELA-RIBEIRO, 2015). Assim, para a inclusão escolar dos surdos não basta apresentar os conteúdos conceituais das disciplinas em LIBRAS. É preciso construir e desenvolver estratégias metodológicas adequadas para o ensino, considerando as suas singularidades de apreensão, abstração e construção dos conhecimentos.

Nesse sentido, Caetano e Lacerda (2011) nos lembram que só podemos conhecer os problemas de uma área "se enfrentarmos a tarefa de ensinar conteúdos cada vez mais complexos para a comunidade surda" (p.156). Mas, como estão as produções teóricometodológicas em torno dessa questão, em especial no que se referem ao ensino de Física, de Química, de Ciências Biológicas, ou seja, no que se referem ao ensino das ciências da vida e da natureza? Há quinze anos, a resposta a essa questão não era a desejável: 
http://dx.doi.org/10.5902/1984686X43701

São valorizadas as pesquisas, bem como discussões sobre a cultura surda com relação à aquisição da língua natural (Língua de Sinais), a oralização, os processos fonoaudiológicos, psicológicos, mas discute-se menos ou não se discute a educação do surdo como um todo. Isto é, com exceção do português, faltam pesquisas na busca por estratégias para ensino de Matemática, Inglês, Geografia, Redação, Química, Física, etc. (OLIVEIRA, 2005, p. 14, apud CAETANO, LACERDA, 2011, p.156).

\section{Um mapeamento dos trabalhos publicados nos últimos cinco anos}

Para se ter um panorama das produções envolvendo o ensino de ciências da vida e da natureza a estudantes surdos, este trabalho tem como objetivo mapear as publicações feitas nos últimos cinco anos em periódicos da área do ensino de ciências e/ou da educação em ciências, classificados como A1 ou A2 no Qualis-Periódicos. Buscamos, ao delimitar o mapeamento a esse interstício, ter acesso às publicações relativamente mais recentes da área, um possível indicativo do que ela considera relevante tratar nesse momento.

De acordo com a CAPES (https://www.capes.gov.br), o Qualis-Periódicos é uma ferramenta usada para classificar a produção científica dos programas de pósgraduação, no que ela se refere aos artigos publicados em periódicos científicos. A classificação procura refletir a importância relativa dos diferentes periódicos para uma determinada área. $\mathrm{Q}$ Qualis afere a qualidade dos artigos publicados a partir da análise da qualidade dos veículos de divulgação, ou seja, dos periódicos científicos. Esses veículos são enquadrados em estratos indicativos da qualidade - A1, A2, A3, A4, B1, B2, B3, B4 e C -, sendo o estrato A1 o mais elevado, e o estrato $C$ o que apresenta peso zero.

Assim, no recorte que fizemos para este trabalho, voltamos a nossa atenção para os estratos que englobavam os periódicos de mais alta qualidade. Justifica-se esse recorte por duas razões. A primeira, para que se limitasse o número de resultados a serem obtidos, considerando-se o grande e crescente índice de publicações da área. O segundo, para que pudéssemos ter como resultados os trabalhos de mais alta qualidade, segundo os critérios do Qualis-Periódicos, o que, em tese, trariam as maiores contribuições para as discussões na área.

Nesse levantamento, buscamos considerar os procedimentos teórico-metodológicos indicados por Assai, Arrigo e Broietti (2018). A primeira etapa do mapeamento dos trabalhos publicados consistiu no estabelecimento dos critérios para a busca dos periódicos no site da ferramenta Qualis-Periódicos, disponível para acesso em https://sucupira.capes.gov.br/sucupira. Esses critérios são descritos no quadro 1: 
http://dx.doi.org/10.5902/1984686X43701

Quadro 1 - Critérios estabelecidos para a busca dos periódicos

\begin{tabular}{|r|l|}
\hline Campo da ferramenta & Critério informado para a busca \\
\hline Evento de classificação & Classificações de periódicos quadriênio 2013-2016 \\
\hline Área de avaliação & Ensino ou Educação \\
\hline ISSN & - \\
\hline Título & $\begin{array}{l}\text { Física ou Química ou Biologia ou Ciências Biológicas ou } \\
\text { Ciências [neste caso, restrito às ciências da vida e da } \\
\text { natureza]. }\end{array}$ \\
\hline Classificação & A1 ou A2 \\
\hline
\end{tabular}

Fonte: elaborado pelos autores (2020).

Apurados os periódicos que atenderam aos critérios de busca no Qualis-Periódicos, passamos à segunda etapa do mapeamento, com a leitura dos títulos dos artigos publicados nesses periódicos nos anos de 2015 a 2019. Para ter acesso a esses dados, nos valemos dos sites dos periódicos e da biblioteca eletrônica Scielo (disponível para acesso em https://www.scielo.org/pt/). Para a seleção dos artigos que tratavam da temática envolvendo o ensino de ciências da vida e da natureza a estudantes surdos, definimos que deveriam estar presentes nos títulos dos artigos alguma(s) das seguintes palavras ou expressões: surdo(a)(s), surdez, inclusão, LIBRAS, língua de sinais, (não)ouvinte(s), deficiência auditiva, inclusão, ou educação inclusiva, bem como os seus correspondentes em inglês ou espanhol.

Ainda que ausentes as palavras ou expressões descritas acima, nos casos nos quais a leitura dos títulos nos deixava em dúvida quanto à inclusão ou não do respectivo artigo, fazíamos a leitura do seu resumo e de suas palavras-chave para tomarmos a decisão de incluir ou descartar aquele artigo em nossa seleção. Uma vez selecionados os artigos, eles foram lidos na íntegra para a apresentação de uma síntese dos mesmos neste trabalho. Após uma primeira leitura flutuante, foram buscados mais especificamente nesses artigos respostas a questionamentos que entendemos pertinentes a este trabalho: Quais aspectos mais específicos do ensino de ciências a surdos foram tratados? De quais sujeitos envolvidos nesse processo se falava? Qual o objetivo do trabalho? Quais resultados foram obtidos? Quais análises e considerações foram feitas e quais implicações foram apontadas? No bojo de uma análise do tipo textual discursiva (SOUZA, GALIAZZI, 2016), entendemos que as sínteses que apresentaremos dos artigos foram o resultado do desenvolvimento de um processo que se iniciou com a desmontagem dos textos, passou pelo estabelecimento de 
http://dx.doi.org/10.5902/1984686X43701

relações e resultou no captar de um novo resultante, isto é, resultou na produção de novas compreensões sobre os discursos que nos foram apresentados.

\section{Os resultados obtidos}

Os resultados obtidos na primeira etapa do mapeamento, o da apuração dos periódicos que atenderam aos nossos critérios de busca (vide quadro 1), estão descritos no quadro 2:

Quadro 2 - Resultados da busca pelos periódicos

\begin{tabular}{|c|c|c|}
\hline & $\begin{array}{c}\text { Ensino } \\
\text { (Qualis A1 ou A2) }\end{array}$ & $\begin{array}{c}\text { Educação } \\
\text { (Qualis A1 ou A2) }\end{array}$ \\
\hline Física & $\begin{array}{l}\text { Revista Brasileira de Ensino de } \\
\text { Física } \\
\text { Caderno Brasileiro de Ensino de } \\
\text { Física }\end{array}$ & - \\
\hline Química & Educación Química & Química Nova \\
\hline $\begin{array}{l}\text { Biologia ou } \\
\text { Ciências } \\
\text { Biológicas }\end{array}$ & $\begin{array}{l}\text { Semina: Ciências Biológicas e da } \\
\text { Saúde }\end{array}$ & Revista de Educación em Biología \\
\hline Ciências & $\begin{array}{l}\text { Enseñanza de las Ciencias } \\
\text { Ensaio: Pesquisa em Educação em } \\
\text { Ciências } \\
\text { Revista de Educacion de las } \\
\text { Ciencias } \\
\text { Revista Eureka sobre Ensenãnza y } \\
\text { Divulgación de las Ciencias }\end{array}$ & $\begin{array}{l}\text { Enseñanza de las Ciencias } \\
\text { Ensaio: Pesquisa em Educação em } \\
\text { Ciências } \\
\text { Revista de Educacion de las } \\
\text { Ciencias } \\
\text { REEC - Revista Electrónica de } \\
\text { Enseñanza de las Ciencias } \\
\text { Revista Brasileira de Pesquisa em } \\
\text { Educação em Ciências } \\
\text { Investigações em Ensino de } \\
\text { Ciências }\end{array}$ \\
\hline
\end{tabular}

Fonte: elaborado pelos autores (2020).

Como percebemos no quadro 2, treze distintos periódicos se enquadraram nos critérios de busca que estabelecemos: Caderno Brasileiro de Ensino de Física; Educación Química; Ensaio: Pesquisa em Educação em Ciências; Enseñanza de las Ciencias; Investigações em Ensino de Ciências; Química Nova; Revista Brasileira de Ensino de Física; Revista Brasileira de Pesquisa em Educação em Ciências; Revista de Educacion de 
http://dx.doi.org/10.5902/1984686X43701

\section{las Ciencias; Revista de Educación em Biología; REEC - Revista Electrónica de Enseñanza} de las Ciencias; Revista Eureka sobre Ensenãnza y Divulgación de las Ciencias; Semina: Ciências Biológicas e da Saúde. Os escopos desses periódicos, de acordo com as informações constantes em seus sites, são os apresentados no quadro 3.

Quadro 3 - Escopos dos periódicos selecionados

(continua)

\begin{tabular}{|c|c|}
\hline Periódico & Escopo \\
\hline $\begin{array}{c}\text { Caderno Brasileiro de Ensino } \\
\text { de Física (CBEF) }\end{array}$ & $\begin{array}{l}\text { Tem por objetivo promover uma disseminação efetiva e } \\
\text { permanente de experiências entre docentes e } \\
\text { pesquisadores, visando a elevar a qualidade do ensino da } \\
\text { Física tanto nas instituições formadoras de novos } \\
\text { professores quanto nas escolas em que esses docentes irão } \\
\text { atuar. }\end{array}$ \\
\hline Educación Química & $\begin{array}{l}\text { Visa preencher o vazio de comunicação e de expressão } \\
\text { entre os professores e os investigadores das ciências } \\
\text { naturais e da educação química, constituindo-se num fórum } \\
\text { de orientação e análise que propicie o melhoramento do } \\
\text { processo ensino aprendizagem da química, para o bem dos } \\
\text { alunos e da sociedade (tradução nossa). }\end{array}$ \\
\hline $\begin{array}{l}\text { Ensaio: Pesquisa em } \\
\text { Educação em Ciências }\end{array}$ & $\begin{array}{l}\text { São publicados artigos de pesquisa inéditos (relatos de } \\
\text { pesquisa empírica ou ensaios teóricos), artigos de revisão } \\
\text { bibliográfica (estado da arte) e resenhas de livros com temas } \\
\text { de interesse ao campo da pesquisa em Educação em } \\
\text { Ciências. }\end{array}$ \\
\hline Enseñanza de las Ciências & $\begin{array}{c}\text { É uma revista dirigida a professores e pesquisadores do } \\
\text { campo da didática das ciências e das matemáticas (tradução } \\
\text { nossa). }\end{array}$ \\
\hline $\begin{array}{l}\text { Investigações em Ensino de } \\
\text { Ciências (IENCI) }\end{array}$ & $\begin{array}{c}\text { É uma revista voltada exclusivamente para a pesquisa na } \\
\text { área de ensino/aprendizagem de ciências (Física, Química, } \\
\text { Biologia ou Ciências Naturais, quando enfocadas de maneira } \\
\text { integrada). }\end{array}$ \\
\hline Química Nova & $\begin{array}{l}\text { Publica artigos com resultados originais de pesquisa, } \\
\text { trabalhos de revisão, divulgação de novos métodos ou } \\
\text { técnicas, educação e assuntos gerais. }\end{array}$ \\
\hline $\begin{array}{c}\text { Revista Brasileira de Ensino } \\
\text { de Física (RBEF) }\end{array}$ & $\begin{array}{l}\text { É uma publicação voltada à melhoria do ensino de Física em } \\
\text { todos os níveis de escolarização. Busca promover e divulgar } \\
\text { a Física e ciências correlatas, contribuindo para a educação } \\
\text { científica da sociedade como um todo. }\end{array}$ \\
\hline
\end{tabular}


http://dx.doi.org/10.5902/1984686X43701

Quadro 3 - Escopos dos periódicos selecionados

(conclusão)

\begin{tabular}{|c|c|}
\hline Periódico & Escopo \\
\hline $\begin{array}{c}\text { Revquista Brasileira de } \\
\text { Ciências (RBPEC) }\end{array}$ & $\begin{array}{c}\text { Tem como objetivo disseminar resultados e reflexões } \\
\text { advindos de investigações conduzidas na área de Educação } \\
\text { em Ciências. }\end{array}$ \\
\hline $\begin{array}{c}\text { Revista de Educación em } \\
\text { Biología }\end{array}$ & $\begin{array}{c}\text { Através de suas diferentes seções busca-se contribuir } \\
\text { conhecimento ao campo da Didática da Biologia em } \\
\text { particular e do Ensino das Ciências em geral (tradução } \\
\text { nossa). }\end{array}$ \\
\hline $\begin{array}{c}\text { Enseñanza Electrónica de las Ciências } \\
\text { (REEC) }\end{array}$ & $\begin{array}{c}\text { Dedicada à pesquisa sobre o ensino e o aprendizado das } \\
\text { ciências experimentais nos diferentes níveis educativos } \\
\text { (infantil, primário, secundário, universidade). }\end{array}$ \\
\hline $\begin{array}{c}\text { Revista Eureka sobre } \\
\text { Ensenãnza y Divulgación de } \\
\text { las Ciencias }\end{array}$ & $\begin{array}{c}\text { Tem uma dupla finalidade. Por um lado, deseja contribuir } \\
\text { para o desenvolvimento do conhecimento no âmbito da } \\
\text { didática das ciências experimentais, tanto a nível teórico } \\
\text { como aplicado. Por outro lado, procura fornecer referências } \\
\text { para a prática da educação científica tanto de professores } \\
\text { como de formadores provenientes do âmbito da educação } \\
\text { não formal (tradução nossa). }\end{array}$ \\
\hline $\begin{array}{c}\text { Semina: Ciências Biológicas } \\
\text { e da Saúde }\end{array}$ & $\begin{array}{c}\text { É uma publicação de divulgação científica e tecnológica. } \\
\text { Publica artigos originais, artigos de revisão, e relatos de } \\
\text { casos ligados à grande área das Ciências Biológicas e da } \\
\text { Saúde. }\end{array}$ \\
\hline
\end{tabular}

Fonte: elaborado pelos autores (2020).

Para a segunda etapa do mapeamento, como dissemos, lemos os títulos de todos os artigos publicados nesses periódicos no período de 2015 a 2019. Houve duas exceções. Para o periódico Revista de Educacion de las Ciencias, não localizamos como disponíveis para acesso livre as informações referentes aos títulos dos artigos publicados no período considerado. No caso do periódico Revista de Educación en Biología, quando deste mapeamento em janeiro de 2020, só estavam disponíveis para consulta os artigos publicados até o final do primeiro semestre de 2019. Ressalvados esses casos, os resultados obtidos em relação aos quantitativos de artigos publicados e de artigos por nós selecionados são os descritos na tabela 1: 
http://dx.doi.org/10.5902/1984686X43701

Tabela 1 - Quantitativos de artigos publicados nos periódicos selecionados

\begin{tabular}{|c|c|c|}
\hline Periódico & $\begin{array}{c}\text { Total de } \\
\text { artigos } \\
\text { publicados }\end{array}$ & $\begin{array}{c}\text { Artigos } \\
\text { sobre } \\
\text { ensino a } \\
\text { surdos }\end{array}$ \\
\hline Caderno Brasileiro de Ensino de Física (CBEF) & 211 & 1 \\
\hline Educación Química & 201 & 0 \\
\hline Ensaio: Pesquisa em Educação em Ciências & 151 & 0 \\
\hline Enseñanza de las Ciências & 170 & 0 \\
\hline Investigações em Ensino de Ciências (IENCI) & 174 & 1 \\
\hline Química Nova & 795 & 0 \\
\hline Revista Brasileira de Ensino de Física (RBEF) & 578 & 1 \\
\hline $\begin{array}{l}\text { Revista Brasileira de Pesquisa em Educação em Ciências } \\
\qquad \text { (RBPEC) }\end{array}$ & 156 & 1 \\
\hline Revista de Educación em Biología & 56 & 0 \\
\hline Revista Electrónica de Enseñanza de las Ciências (REEC) & 133 & 2 \\
\hline $\begin{array}{l}\text { Revista Eureka sobre Ensenãnza y Divulgación de las } \\
\text { Ciencias }\end{array}$ & 211 & 0 \\
\hline Semina: Ciências Biológicas e da Saúde & 88 & 0 \\
\hline 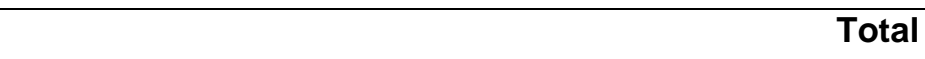 & 2.924 & 6 \\
\hline
\end{tabular}

Fonte: elaborado pelos autores (2020).

Para esses seis artigos, são apresentados no quadro 4 os dados de sua identificação:

Quadro 4 - Dados de identificação dos artigos selecionados

(continua)

\begin{tabular}{|c|c|c|c|c|}
\hline $\mathbf{N}^{\circ}$ & Título do artigo & Autores(as) & Periódico & $\begin{array}{c}\text { Edição de } \\
\text { publicação }\end{array}$ \\
\hline 1 & $\begin{array}{c}\text { Estudos sobre a relação } \\
\text { entre o intérprete de LIBRAS } \\
\text { e o professor: implicações } \\
\text { para o ensino de ciências }\end{array}$ & $\begin{array}{c}\text { Walquíria Dutra de Oliveira, } \\
\text { Anna M. Canavarro Benite }\end{array}$ & RBPEC & $\begin{array}{c}\text { setembro a } \\
\text { dezembro de } \\
2015\end{array}$ \\
\hline 2 & $\begin{array}{c}\text { Ensino de Física para } \\
\text { surdos: um experimento } \\
\text { mecânico e um eletrônico } \\
\text { para o ensino de ondas } \\
\text { sonoras }\end{array}$ & $\begin{array}{c}\text { Deise Benn Pereira Vivas, } \\
\text { Elder Sales Teixeira, Juan } \\
\text { Alberto Leyva Cruz }\end{array}$ & CBEF & abril de 2017 \\
& & & \\
\hline
\end{tabular}


http://dx.doi.org/10.5902/1984686X43701

Quadro 4 - Dados de identificação dos artigos selecionados

(conclusão)

\begin{tabular}{|c|c|c|c|c|}
\hline $\mathbf{N}^{\circ}$ & Título do artigo & Autores(as) & Periódico & $\begin{array}{l}\text { Edição de } \\
\text { publicação }\end{array}$ \\
\hline 3 & $\begin{array}{l}\text { Indicadores da inclusão de } \\
\text { alunos surdos em salas de } \\
\text { aula regulares }\end{array}$ & $\begin{array}{l}\text { Juliane Cristina Molena, } \\
\text { Priscilla Gaia de Andrade e } \\
\text { Estéfano Vizconde Veraszto }\end{array}$ & REEC & $\begin{array}{c}\text { maio a } \\
\text { agosto de } \\
2017\end{array}$ \\
\hline 4 & $\begin{array}{c}\text { A Importância da LIBRAS: } \\
\text { um olhar sobre o ensino de } \\
\text { Química a surdos }\end{array}$ & $\begin{array}{c}\text { Emanuela Pinheiro Nogueira, } \\
\text { Maria Cleide da Silva } \\
\text { Barroso, Caroline de Goes } \\
\text { Sampaio }\end{array}$ & IENCI & $\begin{array}{c}\text { agosto de } \\
2018\end{array}$ \\
\hline 5 & $\begin{array}{c}\text { Proposta didático } \\
\text { experimental para o ensino } \\
\text { inclusivo de } \\
\text { ondas no ensino médio }\end{array}$ & $\begin{array}{l}\text { Márcio Velloso da Silveira, } \\
\text { Ricardo Borges Barthem, } \\
\text { Antonio Carlos dos Santos }\end{array}$ & RBEF & $\begin{array}{l}\text { janeiro a } \\
\text { março de } \\
2019\end{array}$ \\
\hline 6 & $\begin{array}{c}\text { Análise do processo de } \\
\text { ensino-aprendizagem com } \\
\text { discentes surdos no ensino } \\
\text { de ciências: uma revisão } \\
\text { dos trabalhos publicados na } \\
\text { área na última década }\end{array}$ & $\begin{array}{l}\text { Priscilla Gaia de Andrade, } \\
\text { Juliane Cristina Molena, e } \\
\text { Estéfano Vizconde Veraszto }\end{array}$ & REEC & $\begin{array}{c}\text { maio a } \\
\text { agosto de } \\
2019\end{array}$ \\
\hline
\end{tabular}

Fonte: elaborado pelos autores (2020).

\section{O que dizem, em síntese, os seis artigos publicados}

No artigo número 1, Estudos sobre a relação entre o intérprete de LIBRAS e o professor: implicações para o ensino de ciências, Oliveira e Benite (2015) dizem que muito se discute sobre inclusão escolar e sobre o ensino de ciências, mas poucos são os trabalhos que contemplam estas duas áreas. As autoras apontam uma nova realidade educacional para o ensino de ciências para surdos, com a escola e a sala de aula já não podendo funcionar mais com a mesma lógica. Antes da perspectiva da inclusão escolar, as salas de aula estavam organizadas de uma forma na qual o conhecimento científico era o objeto de aprendizado nas aulas de ciências e o professor se configurava como mediador neste processo, lançando mão de métodos e fundamentação teórica e metodológica para a apropriação destes conceitos pelos alunos.

Com o advento da inclusão escolar, o aprendizado do conhecimento científico mediado pelo professor passa a contar com as intervenções de diversos profissionais de apoio, como 
http://dx.doi.org/10.5902/1984686X43701

intérprete de LIBRAS, instrutor de Braile, professor de apoio, e até de estudantes da turma. E como os professores de ciências deveriam se comportar diante desta nova configuração? Nesta sala de aula inclusiva, continuam as autoras do artigo 1, o professor de ciências deveria conhecer, além do conhecimento científico específico, aspectos relativos à aprendizagem dos diferentes grupos sociais, técnicas de ensino-aprendizagem, temas da educação em geral, organização do trabalho escolar, gestão, dentre outros.

Na pesquisa relatada no trabalho descrito neste artigo 1, professores e intérpretes de LIBRAS foram convidados a narrar suas estórias sobre a sala de aula de ciências em diários de aula coletivos. Os resultados indicaram a existência de uma relação de contradição entre o professor de ciências e o intérprete, onde este aponta a negligência e despreparo do professor para atuar com o estudante surdo, enquanto aquele transfere para o intérprete a responsabilidade pelo ensino. As autoras consideram que nem o professor e nem o intérprete são os únicos responsáveis pelo insucesso escolar. Concluem que a escola inclusiva, da forma que está, apaga as diferenças, ao invés de respeitá-las, já que não se estaria reconhecendo a estrutura necessária para a inclusão escolar de surdos.

Os autores do artigo número 2, Ensino de Física para surdos: um experimento mecânico e um eletrônico para o ensino de ondas sonoras, de autoria de Vivas, Teixeira e Cruz (2017), defendem a interação social (alunos-alunos e alunos-professor) para a promoção da construção e do compartilhamento de conhecimentos, e destacam a importância do desenvolvimento de recursos didáticos e das metodologias associadas aos mesmos, pois eles podem possibilitar aos professores se apropriarem de novas formas de ensinar, levando sempre em consideração a realidade do aluno. Discute-se o uso das tecnologias assistivas, entendidas como os recursos e os serviços para a solução de problemas de acessibilidade do aluno na escola. Os autores apontam que, na atualidade, existem poucos estudos a investigar o papel dessas tecnologias no ensino de física.

Buscando contribuir para a superação dessa lacuna, o texto apresenta e discute duas versões (uma mecânica e uma eletrônica) de um experimento didático elaborado pelos autores para tratar de ondas sonoras. O objetivo dessa tecnologia, que ainda não havia sido avaliada em situações reais de sala de aula à época da publicação do artigo, seria o de possibilitar aos alunos surdos (e também aos ouvintes) uma percepção visual das ondas sonoras. Esse seria um caminho para enfrentar a falta de recursos, de metodologias e a inadequação de livros didáticos que, em geral, são obstáculos à apropriação do conhecimento por parte do aluno surdo. Os autores, em suas conclusões, destacam a 
http://dx.doi.org/10.5902/1984686X43701

importância do desenvolvimento de recursos didáticos que sejam significativos para os alunos surdos.

Molena, Andrade e Veraszto (2017), no artigo número 3, Indicadores da inclusão de alunos surdos em salas de aula regulares, enumeram problemas relacionados ao ensino de ciências para discentes surdos: carências na formação pedagógica dos professores, falta de estratégias docentes, avaliação da aprendizagem desconectada da realidade dos alunos surdos, falta de comunicação professor-aluno, grau de abstração do conteúdo, transferência aos intérpretes da responsabilidade de ensinar e avaliar a aprendizagem, desconhecimento do currículo escolar e das modificações propostas para o âmbito da educação especial.

Diante desses problemas, o trabalho buscou levantar fatores que indicariam a inclusão dos alunos surdos nas salas de ensino regular. A partir da análise das entrevistas feitas com professores e intérpretes envolvidos no processo de ensino-aprendizagem, as seguintes categorias emergiram: papel do intérprete, recursos especiais necessários, planejamento e discussão das ações necessárias, funções do atendimento educacional especializado, equiparação das oportunidades educacionais dos alunos surdos comparada aos alunos ouvintes, flexibilidade na correção das atividades escritas, conhecimento da cultura surda, respeito à condição bilíngue e à LIBRAS, inclusão dos alunos surdos na sala de aula regular, flexibilidade para adaptação curricular, e avaliações.

Ainda que ressalvando a falta de consulta aos próprios alunos surdos, os autores do artigo 3 consideraram que, na unidade escolar investigada, esse alunos estavam a um passo de serem efetivamente incluídos no processo de ensino-aprendizagem. Isso, apesar de restarem aspectos que precisassem ser aprimorados. Na conclusão, salientaram que, enquanto vivermos em uma sociedade capitalista que se pauta em padrões de normalidade e exclui o que seja diferentes a eles, tratar da inclusão é algo fundamental.

O artigo número 4, A Importância da LIBRAS: um olhar sobre o ensino de Química a surdos, foi escrito por Nogueira, Barroso e Sampaio (2018). As autoras argumentam que o ensino de química é importante, pois dá às pessoas a chance de melhor compreenderem as suas vidas. Mas, ele enfrenta diversos desafios e, assim, requer ser bem pensado. Elas sugerem o uso de estratégias e recursos adequados, principalmente no caso de alunos com necessidades educacionais especiais. Para elas, no caso dos surdos, a língua de sinais tem papel fundamental.

O trabalho descrito neste artigo 4, constituindo-se como uma revisão de literatura, teve como objetivo geral a investigação do papel da língua de sinais para os surdos, tendo como 
foco o ensino de química e suas barreiras. As autoras defendem que o professor também saiba a língua de sinais para que possa se comunicar diretamente com o aluno surdo, não deixando essa responsabilidade apenas para o intérprete. E dizem que todo recurso visual (como vídeo aulas, slides, desenhos, documentários, práticas em laboratório etc.) é positivo para os alunos, surdos ou não, embora sejam poucas as escolas que utilizem esses recursos constantemente. Além disso, apontam que outro problema preocupante seria a falta de sinais de química, ou seja, aqueles que envolvam, representam e transmitam os conceitos químicos.

As autoras concluem no sentido de que há falta de sinais relacionados aos conteúdos de química, o que seria uma dificultador para a aprendizagem. Além disso, concluem que os professores não sabem LIBRAS e, mesmo no caso dos que sabem, precisam dos intérpretes. As autoras ainda mencionam que os intérpretes precisariam ser fluentes tanto em LIBRAS quanto conhecedores de saberes da química, para um bom desenrolar das aulas.

Silveira, Barthem e Santos (2019), no artigo número 5, Proposta didático experimental para o ensino inclusivo de onda no ensino médio, buscando superar os problemas geralmente relacionados ao ensino desse conteúdo, desenvolveram dois experimentos na plataforma Arduíno que converteriam frequências invisíveis e inaudíveis em frequências que sensibilizariam outros sentidos. As aplicações poderiam ser utilizadas inclusive por estudantes com deficiência visual ou auditiva, permitindo uma integração de todos em uma turma mista.

Em um dos experimentos, denominado o som que o surdo pode ver e o cego pode ouvir, a ideia foi a de apresentar, no caso do aluno surdo, um aparato capaz de produzir um som inaudível ao ser humano, cujo eco fosse captado na forma de luzes coloridas. O estímulo visual, através dos LEDs coloridos, seria fundamental para a percepção e compreensão do fenômeno. Os alunos de uma turma mista estariam, assim, em igualdade de condições para a compreensão do fenômeno. No caso do outro experimento, ele foi denominado por a luz que o cego pode ouvir e o surdo pode ver.

Os autores defendem que as atividades propostas permitiriam uma experiência sensorial a alunos cegos e surdos em classes mistas, tendo o potencial de permitir que 0 aluno "deficiente visual ou auditivo" estabeleça relações com o aprendizado de física, de forma a adquirir conceitos mais adequados, bem como padrões de raciocínio mais elaborados. 
No artigo número 6, Análise do processo de ensino-aprendizagem com discentes surdos no ensino de ciências: uma revisão dos trabalhos publicados na área na última década, os autores Andrade, Molena e Veraszto (2019), os mesmos do artigo 3, investigaram os principais desafios enfrentados pelos docentes ao mediarem conceitos científicos aos alunos surdos ao longo do processo de ensino-aprendizagem. Para isso, fizeram um levantamento bibliográfico de artigos publicados nos últimos dez anos na área.

Dos artigos encontrados, apenas seis, publicados entre 2006 e 2012, contemplavam o tema da pesquisa: Um estudo de possíveis correlações entre representações docentes e o ensino de ciências e matemática para surdos (Borges e Costa, 2010); Estudo de planejamento e design de um módulo institucional sobre o sistema respiratório: o ensino de ciências para surdos (Queiroz, Silva, Macedo e Benite, 2012); Ensino de ciências para deficientes auditivos: um estudo sobre a produção de narrativas em classes regulares inclusivas (Oliveira, Melo e Benite, 2012); Terminologias químicas em libras: a utilização de sinais na aprendizagem de alunos surdos (Souza e Silveira, 2011); Aula de química e surdez: sobre interações pedagógicas mediadas pela visão" (Pereira, Benite e Benite, 2011); Utilizar as TIC para ensinar física a alunos surdos: estudo de caso sobre o tema 'a luz e a visão (Paiva, 2006).

A partir das análises desses artigos, os autores criaram os seguintes eixos temáticos para contemplar as discussões em torno dos objetivos propostos: concepções docentes acerca da educação especial e inclusão escolar, os desafios enfrentados pelos docentes no processo de ensino-aprendizagem com discentes surdos, e reflexão dos desafios dos professores no processo de ensino-aprendizagem. Segundo os autores, os trabalhos consideraram que ainda seriam necessários avanços consideráveis na inclusão de discentes surdos e que poucos seriam os professores que compreendem a educação especial e a inclusão escolar. Além disso, todos os artigos científicos pontuaram quase que os mesmos desafios relacionados à formação docente, à prática docente, ao intérprete, à comunicação, às dificuldades institucionais e estruturais, e à insuficiência de pesquisas na área do ensino de ciências para discentes surdos.

Os autores concluem que são necessárias ações conjuntas para a superação dos desafios encontrados, sendo fundamentais a preparação e valorização do profissional da educação, bem como estratégias eficientes e propostas pedagógicas próximas da realidade dos alunos e professores. 
http://dx.doi.org/10.5902/1984686X43701

\section{À guisa de conclusão, algumas reflexões sobre o panorama que se apresenta}

Neste trabalho, nós, professores e formadores de professores de ciências da vida e da natureza, nos propusemos a mapear artigos que tratassem do ensino de ciências a estudantes surdos. Para se ter um panorama das produções recentes envolvendo o ensino de ciências da vida e da natureza a estudantes surdos, buscamos mapear as publicações feitas nos últimos cinco anos em conceituados periódicos da área do ensino de ciências e/ou da educação em ciências, classificados como A1 ou A2 no Qualis-Periódicos.

Nosso interesse de pesquisa surgiu dos desafios que precisam ser enfrentados para que tenhamos uma efetiva inclusão escolar desses estudantes. Dentre os desafios apontados pela literatura estão os relacionados à formação docente e à deficiência de fundamentos teóricos e práticos para o exercício da função docente, em especial, de estratégias metodológicas adequadas para o ensino de ciências a estudantes surdos. Importante, portanto, nos valermos dos resultados de pesquisas e dos trabalhos publicados na área como forma de obtermos subsídios para melhor trilharmos os nossos caminhos.

No entanto, ainda que concordemos com Menezes e Lacerda (2017), no sentido de que devemos fugir de extremismos e pessimismos que, em geral, nos imobilizam e de que houve avanços significativos no campo das políticas públicas de educação e inclusão, é preciso dizer que foi baixo o número de resultados obtidos. Uma referência já mencionada neste trabalho, Oliveira (2005), nos alertava que faltavam pesquisas sobre estratégias para ensino das ciências aos surdos, dentre outras disciplinas. E essa falta também ficou consignada nos resultados que obtivemos. Dos quase três milhares de trabalhos publicados em periódicos conceituados da área de educação ou ensino de ciências nos últimos cinco anos, apenas seis, isto é, cerca de $0,2 \%$ do total, tinham os surdos como os sujeitos aprendentes considerados.

Quando nos debruçamos sobre esses seis artigos, louváveis nesse esforço de contribuírem para as discussões na área, vemos que eles fizeram, em geral, o apontamento dos desafios postos nessa questão da inclusão escolar dos surdos. Especificamente em relação às ciências, poderíamos classificá-los em quatro categorias: dois deles apresentaram propostas metodológicas para o ensino; dois, olhando para os intérpretes ou para os sinais, centraram a discussão na LIBRAS; um propunha indicadores da inclusão de alunos surdos em salas de aula regulares; um fazia um levantamento similar ao que aqui nos propusemos, 
http://dx.doi.org/10.5902/1984686X43701

mas usando fontes diferentes e cobrindo um período também diferente. Interessante notar que esse último trabalho também apontou um relativo baixo número de pesquisas na área do ensino de ciências para discentes surdos. Desses dois mapeamentos, vemos que os trabalhos, além de reduzidos em número, têm mais de um foco de discussão. Além disso, em alguns casos, alguns autores aparecem em mais de um trabalho, indicando uma redução ainda mais acentuada em relação ao número de pesquisadores envolvidos nas publicações.

Assim, ainda que consideradas as limitações do presente mapeamento que fizemos, fica patente o baixo número de publicações a tratar do ensino de ciências para estudantes surdos. Não é fácil a tarefa de apontar as causas disso, mas algumas hipóteses podem ser levantadas para a discussão. Uma delas seria a de que esses trabalhos têm sido publicados em quantidades e qualidades significativas sob outros formatos (dissertações, teses, comunicações, livros etc.), ou em periódicos específicos de outras áreas (que tratam de inclusão, por exemplo), ou em outros periódicos de nossa área. Nesse caso, trabalhos sobre o ensino de ciências a surdos estariam sim sendo desenvolvidos, mas os relatos das experiências ou os resultados das investigações que os constituiriam não estariam sendo submetidos ou sendo aceitos para publicação nos periódicos que foram objeto de nosso mapeamento. Por razões que precisariam ser investigadas em outros estudos, esses trabalhos estariam encontrando abrigo em outros locais.

Outra hipótese, mais preocupante, é a de que esses trabalhos realmente não têm sido desenvolvidos e publicados, apesar da importância que eles teriam para a inclusão escolar dos surdos em relação às ciências, como mostram as referências aqui discutidas. Assim, os complexos desafios apontados pela literatura poderiam estar sendo um desestímulo para uma atuação mais efetiva em direção à inclusão dos estudantes surdos de ciências. Mas, só poderíamos confirmar esse entendimento a partir de trabalhos que se voltassem especificamente para a investigação das causas para o estabelecimento dessa situação e para a proposição de soluções para a reversão da mesma.

Acreditamos, porém, na necessidade de aprofundamento de alguns pontos da pesquisa sobre a inclusão de alunos surdos. Percebemos, por motivos variados, que muitos consideram o aluno surdo igual ao aluno ouvinte, ou seja, eles têm que ser tratados da mesma maneira em sala. Ao contrário, tem-se tornado explícito, para nós pesquisadores, que compreender a educação de surdos como um encontro de culturas é essencial para a pesquisa acadêmica e, consequentemente, para a inclusão deste grupo em sala de aula. Em nossa leitura, as pesquisas futuras podem ter como meta perseguir as relações entre a 
cultura dos alunos surdos, o domínio dos conteúdos e as formas específicas do processo de construção dos conceitos e dos mecanismos de argumentação desses alunos. Indagamos: O que significa para um aluno surdo ter e utilizar em seu cotidiano uma linguagem gestual e visual - Libras - e uma língua escrita em Português? Se utiliza as duas formas de expressão, estas não seriam produtoras de ambiguidades, capazes de condicionar a compreensão dos conceitos por parte dos alunos surdos? Se os objetos são representados por sinais, como isso afeta a construção de conceitos científicos? Qual o papel que uma imagem, uma fotografia ou um vídeo exercem na compreensão do mundo físico por estes alunos?

Tais questões apontam para se pensar no uso de analogias e metáforas em situações de ensino e aprendizagem em turmas de alunos surdos. Não temos dúvidas de que a diversificação de estratégias didáticas em sala de aula é muito importante, tanto para o aluno surdo como para o ouvinte, e as analogias, sobremaneira, incitam a participação dos alunos, relacionando os mesmos conceitos em situações diversas. Um indicativo para novas pesquisas, centrado nas interações do aluno com as atividades propostas, é de como as situações de ensino e de aprendizagem são marcadas pela compreensão das analogias e pela permanência das metáforas de uma atividade para outra. Parece-nos que a compreensão pelo aluno surdo da manutenção de uma metáfora de uma situação de ensino para outra ajuda no entendimento do conceito que está sendo trabalhado. Estas questões que trazemos sugerem a importância de um grupo de pesquisa interdisciplinar, que consiga articular, pelo menos, os domínios da cultura surda, do conhecimento científico e da linguagem.

\section{Referências}

ANDRADE, Priscilla Gaia de; MOLENA, Juliane Cristina; VERASZTO, Estéfano Vizconde. Análise do processo de ensino-aprendizagem com discentes surdos no ensino de ciências: uma revisão dos trabalhos publicados na área na última década. Revista Electrónica de Enseñanza de las Ciencias, v. 18, n. 2, p. 361-386, 2019. Disponível em: http://reec.uvigo.es/volumenes/volumen18/REEC_18_2_4_ex1185.pdf. Acesso em 9 abr. 2020.

ASSAI, Natany Dayani de Souza; ARRIGO, Viviane; BROIETTI, Fabiele Cristiane Dias. Uma proposta de mapeamento em periódicos nacionais da área de ensino de ciências.

REPPE: Revista do Programa de Pós-Graduação em Ensino - Universidade Estadual do Norte do Paraná. Cornélio Procópio, v. 2, n. 1, p. 150-166, 2018. Disponível em: http://seer.uenp.edu.br/index.php/reppe/article/view/1380/675. Acesso em 9 abr. 2020. 
BENITE, Anna Maria Canavarro; BENITE, Cláudio Roberto Machado; VILELA-RIBEIRO, Eveline Borges. Educação inclusiva, ensino de Ciências e linguagem científica: possìveis relações. Revista Educação Especial, v. 28, n. 51, p. 83-92, 2015. Disponível em: https://periodicos.ufsm.br/educacaoespecial/article/view/7687. Acesso em 15 abr. 2020.

CAETANO, Juliana Fonseca; LACERDA, Cristina Broglia Feitosa de. Libras no currículo de cursos de licenciatura: estudando o caso das Ciências Biológicas. In: GÓES, Alexandre Morand et al. Língua Brasileira de Sinais - Libras: uma introdução. Coleção UAB-UFSCar Pedagogia. São Carlos: Depto. Prod. Gráfica da UFSCar, 2011.

CAMPOS, Mariana de Lima Isaac Leandro. Educação Inclusiva para surdos e as políticas vigentes. In: GÓES, Alexandre Morand et al. Língua Brasileira de Sinais - Libras: uma introdução. Coleção UAB-UFSCar Pedagogia. São Carlos: Depto. Prod. Gráfica da UFSCar, 2011.

ESPOTE, Roberta; SERRALHA, Conceição Aparecida; SCORSOLINI-COMIN, Fabio Inclusão de surdos: revisão integrativa da literatura científica. Psico-USF, Itatiba, v. 18, n. 1, p. 77-88, Apr. 2013. Disponível em: http://www.scielo.br/pdf/pusf/v18n1/v18n1a09.pdf. Acesso em 9 abr. 2020.

FELIPE, Tanya A. O discurso verbo-visual na língua brasileira de sinais - Libras.

Bakhtiniana. V. 8, n. 2, p. 67-89, 2013. Disponível em: http://www.scielo.br/pdf/bak/v8n2/05.pdf. Acesso em 15 abr. 2020.

GESSER, Audrei. Do patalógico ao cultural na surdez: para além de um e de outro ou para uma reflexão crítica dos paradigmas. Trab. Ling. Aplic. Campinas, v. 47, n. 1, p. 223-239, 2008. Disponível em:

https://pdfs.semanticscholar.org/e559/0a30976d8a7a55b58f003408c8c71f0d30b9.pdf. Acesso em 15 abr. 2020.

KARNOPP, Lodenir Becker. Produções culturais em língua brasileira de sinais. Letras de Hoje, v. 48, n. 3, p. 407-413, 2013. Disponível em:

http://revistaseletronicas.pucrs.br/ojs/index.php/fale/article/view/12616. Acesso em 15 abr. 2020.

MENEZES, Adriane Melo de Castro; LACERDA, Cristina Broglia Feitosa de. Tradutoresintérpretes de línguas de sinais: funções e atuação nas redes de ensino. Revista Educação Especial, v. 30, n. 57, p. 251-262, 2017. Disponível em: https://periodicos.ufsm.br/educacaoespecial/article/view/22412. Acesso em 15 abr. 2020.

MOLENA, Juliane Cristina; ANDRADE, Priscilla Gaia de; VERASZTO, Estéfano Vizconde. Indicadores da inclusão de alunos surdos em salas de aula regulares. Revista Electrónica de Enseñanza de las Ciencias, v. 16, n. 2, p. 257-279, 2017. Disponível em: http://reec.uvigo.es/volumenes/volumen16/REEC_16_2_5_ex1177.pdf. Acesso em 9 abr. 2020.

NOGUEIRA, Emanuela Pinheiro; BARROSO, Maria Cleide da Silva; SAMPAIO, Caroline de Goes. A Importância da LIBRAS: um olhar sobre o ensino de Química a surdos.

Investigações em Ensino de Ciências. V. 23, n. 2, p. 49-64, 2018. Disponível em: https://www.if.ufrgs.br/cref/ojs/index.php/ienci/article/view/861. Acesso em 9 abr. 2020. 
OLIVEIRA, Janine Soares de. A comunidade surda: perfil barreiras e caminhos promissores no processo de ensino-aprendizagem em matemática. Dissertação. CEFET, Rio de Janeiro, 2005.

OLIVEIRA, Walquíria Dutra de; BENITE, Anna M. Canavarro. Estudos sobre a relação entre o intérprete de LIBRAS e o professor: implicações para o ensino de ciências. Revista Brasileira De Pesquisa Em Educação Em Ciências. Belo Horizonte, v. 15, n. 3, p. 597626, 2015. Disponível em: https://periodicos.ufmg.br/index.php/rbpec/article/view/4331. Acesso em 9 abr. 2020.

PERLIN, Gladis; STROBEL, Karin. História cultural dos surdos: desafio contemporâneo. Educar em Revista. Curitiba, Edição Especial, n. 2, p. 17-31, 2014. Disponível em: http://www.scielo.br/pdf/er/nspe-2/03.pdf. Acesso em 15 abr. 2020.

SILVEIRA, Márcio Velloso da; BARTHEM, Ricardo Borges; SANTOS, Antonio Carlos dos. Proposta didático experimental para o ensino inclusivo de ondas no ensino médio. Rev. Bras. Ensino Fís., São Paulo, v. 41, n. 1, 2019. Disponível em: http://www.scielo.br/scielo.php?script=sci_arttext\&pid=S1806$11172019000100606 \&$ Ing=en\&nrm=iso. Acesso em 09 Abr. 2020.

SOUSA, Robson Simplício de.; GALIAZZI, Maria do Carmo. Compreensões acerca da Hermenêutica na Análise Textual Discursiva: marcas teórico-metodológicas à investigação. Contexto \& Educação, Ano 31, n. 100, p. 33-55, 2016. Disponível em: https://www.revistas.unijui.edu.br/index.php/contextoeducacao/article/view/6395. Acesso em 24 Fev. 2021.

SKLIAR, Carlos e QUADROS, Ronice. Invertendo epistemologicamente o problema da inclusão: os ouvintes no mundo dos surdos. Estilos clin. [online]. Vol.5, n.9, 2000, p.32-51. Disponível em: http://www.revistas.usp.br/estic/article/view/60913. Acesso em 15 Abr. 2020.

VIVAS, Deise Benn Pereira; TEIXEIRA, Elder Sales; CRUZ, Juan Alberto Leyva. Ensino de Física para surdos: um experimento mecânico e um eletrônico para o ensino de ondas sonoras. Caderno Brasileiro de Ensino de Física, Florianópolis, v. 34, n. 1, p. 197-215, maio 2017. Disponível em: https://periodicos.ufsc.br/index.php/fisica/article/view/21757941.2017v34n1p197. Acesso em 9 abr. 2020.

\section{Notas}

${ }^{1}$ Para Strobel (citada em Perlin e Strobel, 2014), cultura surda é o jeito de o sujeito surdo entender o mundo e de modificá-lo a fim de torná-lo acessível e habitável, ajustando-o com as suas percepções visuais, que contribuem para a definição das identidades surdas e das "almas" das comunidades surdas. Isto significa que abrange a língua, as ideias, as crenças, os costumes e os hábitos do povo surdo.

${ }^{2}$ Ainda que a autora nos alerte de que isso não significa que o surdo também não construa outras culturas e identidades, por exemplo, na língua portuguesa. 